\title{
Characterization of Ribavirin Aerosol With Small Particle Aerosol Generator and Vibrating Mesh Micropump Aerosol Technologies
}

\author{
Brian K Walsh RRT-NPS FAARC, Peter Betit RRT-NPS FAARC, \\ James B Fink PhD RRT FAARC, Luis M Pereira PhD, and John Arnold MD
}

\begin{abstract}
BACKGROUND: Ribavirin is an antiviral drug that can be administered by inhalation. Despite advancements in the oral delivery of this medication, there has been a renewed interested in delivering ribavirin via the pulmonary system. Although data are not conclusive that inhaled ribavirin improves outcomes, we set out to determine whether delivery by a newer generation nebulizer, the vibrating mesh micropump, was as effective as the recommended small-particle aerosol generator system. METHODS: We compared the physicochemical makeup and concentrations of ribavirin before and after nebulization with $0.9 \% \mathrm{NaCl}$ and sterile water. An Andersen cascade impactor was used to determine particle size distribution and mass median aerodynamic diameter, and an absolute filter was used to measure total aerosol emitted output and inhaled dose during mechanical ventilation and spontaneous breathing. Ribavirin was analyzed and quantified using high-performance liquid chromatography with tandem mass spectrometric detection. RESULTS: Ribavirin was found to be stable in both $0.9 \%$ aqueous $\mathrm{NaCl}$ and sterile water with an $r^{2}$ value of 0.96 and identical coefficients of variation with no difference in drug concentration before and after nebulization with the vibrating mesh micropump. The small-particle aerosol generator produced a smaller mass median aerodynamic diameter $(1.84 \mu \mathrm{m})$ than the vibrating mesh micropump (3.63 $\mu \mathrm{m}, P=.02)$; however, there was no significant difference in the proportion of drug mass in the 0.7-4.7- $\mu \mathrm{m}$ particle range. Total drug delivery was similar with the smallparticle aerosol generator and vibrating mesh micropump in both spontaneously breathing $(P=.77)$ and mechanical ventilation $(P=.48)$ models. CONCLUSIONS: The vibrating mesh micropump nebulizer may provide an effective alternative to the small-particle aerosol generator in administration of ribavirin using $\mathrm{NaCl}$ or sterile water, both on and off the ventilator. Further clinical studies are needed to compare efficacy. Key words: ribavirin; vibrating mesh nebulizer; small-particle aerosol generator; mass median aerodynamic diameter; mechanical ventilation. [Respir Care 2016;61(5):577-585. @ 2016 Daedalus Enterprises]
\end{abstract}

\section{Introduction}

The antiviral drug ribavirin was developed for the treatment of respiratory syncytial virus in symptomatic infants

\footnotetext{
Mr Walsh, Dr Pereira, and Dr Arnold are affiliated with the Department of Anesthesiology, Perioperative and Pain Medicine, and Mr Betit is affiliated with the Department of Respiratory Care, Boston Children's Hospital, Boston, Massachusetts. Mr Walsh and Dr Arnold are affiliated with the Department of Anesthesia, Harvard Medical School is also affiliated with the Department of Anesthesia, Harvard Medical School, Boston, Massachusetts. Dr Arnold is also affiliated with the Department of Critical Care Medicine, Children's Hospital, Boston, Massachusetts. Dr Fink is affiliated with James B Fink, LLC, San Mateo, California, and the Department of Respiratory Therapy, Georgia State University, Atlanta, Georgia.
}

and was cleared by the FDA in $1986,{ }^{1}$ and although this medication was initially promising, it failed to have any significant impact on mortality or hospital duration in this population. ${ }^{2}$ Despite the disappointing results of earlier

\footnotetext{
Mr Walsh, Mr Betit, Dr Pereira, and Dr Arnold have disclosed a relationship with Aerogen. Dr Fink has disclosed relationships with Aerogen, Bayer, Boerhinger Ingleheim, Dance Biopharm, Novartis, ONY, Parion, Aridis, and the World Health Organization.
}

Correspondence: Brian K Walsh RRT-NPS FAARC, Department of Anesthesiology, Perioperative and Pain Medicine, 300 Longwood Avenue, Boston, MA 02115. E-mail: brian.walsh@childrens.harvard.edu.

DOI: $10.4187 /$ respcare. 04383 
studies, ribavirin has been shown to be an important treatment option in the management of respiratory syncytial virus infections in adult and pediatric patients with immunocompromised conditions associated with solid-organ and hematopoietic stem cell transplantation. ${ }^{3}$ It has been shown to be effective at halting the progression of infection from the upper to the lower respiratory tract and at reducing the associated morbidity and mortality. ${ }^{1}$

\section{See the Related Editorial on Page 714}

Ribavirin has been administered orally, intravenously, and by inhalation. ${ }^{4-7}$ High-dose, short-duration aerosolized ribavirin therapy $(60 \mathrm{mg} / \mathrm{mL})$, administered for $2 \mathrm{~h} 3$ times $/ \mathrm{d}$ has been shown to be well-tolerated by patients while achieving the same ribavirin blood and secretion levels as the previously recommended $20 \mathrm{~h}$ of continuous therapy. ${ }^{8}$ The shorter intermittent-duration administration of aerosol has become the standard inhalation schedule because it has been proven to be equally effective as the continuous delivery while reducing environmental contamination. ${ }^{9}$

Ribavirin was cleared for inhalation with the pneumatic small-particle aerosol generator (small-particle aerosol generator-2) device, which was initially designed for administration to small children via tent and later mechanical ventilation. ${ }^{10}$ The small-particle aerosol generator- 2 was specifically designed and approved for the administration of ribavirin. Reports of aerosol characteristics of ribavirin have been limited. Newth and Clark ${ }^{11}$ in 1989 reported that the small-particle aerosol generator-2 produced particles of $2 \%$ ribavirin with a mass median aerodynamic diameter (MMAD) of $1.2 \mu \mathrm{m}$, with $93 \%$ of particles $<5 \mu \mathrm{m}$ and $70-75 \%$ of particles in the $1-5-\mu \mathrm{m}$ range, with performance consistent over nebulization time up to $16 \mathrm{~h}$.

Since the introduction of the small-particle aerosol generator-2, there have been significant advances in aerosol technology. The most recent advancement has been the vibrating mesh micropump aerosol generator that has been reported with a variety of interfaces common to acute and critical care applications (eg, mask, mouthpiece, high-flow nasal cannula, and both invasive and noninvasive mechanical ventilation). ${ }^{12-16}$ The vibrating mesh micropump is commercially available and has been shown to deliver more aerosolized drug, such as salbutamol, than traditional jet nebulizers in neonatal, pediatric, and adult models. ${ }^{17}$ The small-particle aerosol generator-2 is a large-volume pneumatic nebulizer with a large reservoir, designed for continuous nebulization. In contrast, the vibrating mesh nebulizer is a small-volume nebulizer that is commonly marketed with a continuous tube set and syringe for use with a volumetric pump (not used in this study).

The recommended diluent for ribavirin is sterile water, which is known to be an irritant to the airway. Some of this

\section{QUICK LOOK}

\section{Current knowledge}

There is a renewed interest in providing aerosolized ribavirin to a select patient population with viral pulmonary infections. Currently, there is only one aerosol delivery system FDA-cleared to deliver ribavirin that is infrequently utilized and laborious to set up and maintain.

\section{What this paper contributes to our knowledge}

The newer generation vibrating mesh micropump aerosol technology may be an acceptable alternative to the small-particle aerosol generator. The vibrating mesh micropump may be preferred due to familiarity and in clinical scenarios in which portability and lack of additional flow is ideal.

effect may be mitigated with the small particle aerosol generator by use of a secondary drying chamber that serves to reduce particle sizes through evaporation thereby reducing the mass of hypotonic particles inhaled. The vibrating mesh micropump produces aerosol without use of a drying chamber, so that hypotonic ribavirin mixed according to the manufacturer's label may negatively impact the respiratory system, potentially propagating cough or bronchospasm. Consequently, we set out to determine the stability of ribavirin mixed with normal saline.

Our primary goals were to: (1) determine the stability of ribavirin mixed with normal saline as compared with sterile water for use with the vibrating mesh micropump, (2) determine the effects of the vibrating mesh micropump technology on the physicochemical makeup and concentration of ribavirin, and (3) characterize ribavirin delivery by particle size distribution and median aerodynamic diameter calculations and aerosol output within 2 common models of delivery (mechanical ventilation and mask) from the smallparticle aerosol generator-2 and compare the performance of the vibrating mesh micropump with a similar drug formulation and strength. Such data would allow clinicians to determine how the vibrating mesh micropump method for aerosol administration compares with the small-particle aerosol generator-2 during administration of ribavirin.

\section{Methods}

\section{Devices}

An electronic vibrating mesh micropump nebulizer driven by an electronic control module (Aerogen Solo, Aeroneb ProX, Aerogen Ireland Ltd, Galway, Ireland) and a smallparticle aerosol generator-2 (Valeant Pharmaceutics, Montreal, Canada) were set up and operated according to the 
manufacturer's recommendations. To effectively compare performance between the large- and small-volume reservoirs, we used an absolute volume in the vibrating mesh micropump and a timed delivery with the small-particle aerosol generator-2. The estimated small-particle aerosol generator-2 large-volume nebulizer output is $12 \mathrm{~mL} / \mathrm{h}$, or $0.2 \mathrm{~mL} / \mathrm{min}$. Due to the design of the small-particle aerosol generator-2 nebulizer, we operated it with $20 \mathrm{~mL}$ in the reservoir to ensure the most efficient and consistent output. To compare emitted doses, we conducted 5-min timed small-particle aerosol generator dosing to an absolute volume of $1 \mathrm{~mL}$ placed in the vibrating mesh micropump that requires approximately 2 min to deliver.

\section{Drug Formulation}

The nebulized formulation of reagent grade ribavirin (Sigma-Aldrich, St. Louis, Missouri) was reconstituted to a concentration of $60 \mathrm{mg} / \mathrm{mL}$ mixed in sterile water for the small-particle aerosol generator and $0.9 \%$ aqueous $\mathrm{NaCl}$ for the vibrating mesh micropump.

\section{Experimental Design}

In distinct experimental steps, the following parameters were tested in triplicate unless otherwise specified: (1) stability of ribavirin in $0.9 \%$ aqueous $\mathrm{NaCl}$ and sterile $\mathrm{H}_{2} \mathrm{O}$, (2) pre- and post-nebulization of vibrating mesh micropump, (3) particle size distribution with MMAD calculations, and (4) aerosol output emitted using 2 models of delivery (mechanical ventilation and spontaneous breathing).

\section{Drug Stability in Solution}

To determine the stability of ribavirin mixed with normal saline compared with sterile water, $60-\mathrm{mg} / \mathrm{mL}$ solutions of ribavirin in water and normal saline were analyzed by high-performance liquid chromatography with tandem mass spectrometric detection.

\section{Comparison of Ribavirin Before and After Vibrating Mesh Micropump Nebulization}

We compared the physicochemical makeup and concentrations of the ribavirin before and after nebulization. $1 \mathrm{~mL}$ of ribavirin was placed in the vibrating mesh micropump, and emitted aerosol was collected by using a $50-\mathrm{mL}$ tube sealed to the outlet of the nebulizer. Since the vibrating mesh micropump operates without gas flow, emitted aerosol was collected and allowed to transition from aerosol to liquid through sedimentation and then assayed. Samples of the formulation before and after nebulization were compared by high-performance liquid chromatography/tandem mass spectrometry.

\section{Particle Size Distribution}

Aerosol samples were collected with an 8-stage Andersen cascade impactor (Copley Scientific, Nottingham, United Kingdom) operated at $28.3 \mathrm{~L} / \mathrm{min}$ as described by the United States Pharmacopoeia. Aerosol emitted from each nebulizer was collected for $2 \mathrm{~min}$. Normal saline was used to wash the throat $(10 \mathrm{~mL})$, and each stage $(5 \mathrm{~mL})$ of the impactor was analyzed by high-performance liquid chromatography/tandem mass spectrometry to quantify drug mass deposited.

MMAD and geometric SD were calculated by entering the results into the web-based MMAD calculator (www. mmadcalculator.com). This website uses the approach recommended by ISO 27427 (Nebulizing Systems and Components), which is to use the 2 values, one above and one below the $50 \%$ cumulative collection efficiency value, to plot the line representing the size distribution. ${ }^{18}$

\section{In Vitro Model}

Spontaneous Breathing. An active test lung (QuickLung Jr. Breather, IngMar Medical, Pittsburgh, Pennsylvania) was set to eupnea at a rate of 20 breaths $/ \mathrm{min}$, tidal volume of $200 \mathrm{~mL}$, with compliance of $15 \mathrm{~mL} / \mathrm{cm} \mathrm{H}_{2} \mathrm{O}$ and a resistance of $20 \mathrm{~cm} \mathrm{H}_{2} \mathrm{O} / \mathrm{L} / \mathrm{s}$.

An absolute filter (Respirgard II 303, Vital Signs, CareFusion, San Diego, California) was placed before the inlet to the test lung to collect inhaled aerosol. After each dose, the absolute filter was removed and eluted with $10 \mathrm{~mL}$ of normal saline for $2 \mathrm{~min}$ of moderate agitation. Samples were collected and stored at $-80^{\circ} \mathrm{C}$ for assay.

The small-particle aerosol generator- 2 nebulizer was set up according to the manufacturer's recommendations for a face mask with the manufacturer-provided T-piece directly connected to the absolute filter that was attached to the spontaneously breathing lung model. The small-particle aerosol generator- 2 regulator pressure was set to $26 \mathrm{psi}$, nebulizer flow was set to $8 \mathrm{~L} / \mathrm{min}$, and drying air flow rate was set to $4 \mathrm{~L} / \mathrm{min}$ for a total flow of $12 \mathrm{~L} / \mathrm{min}$. The small-particle aerosol generator was operated for $5 \mathrm{~min}$ for an estimated $1 \mathrm{~mL}$ of drug.

The vibrating mesh micropump was set up with the manufacturer-provided T-piece directly connected to the filter attached to the test lung. One $\mathrm{mL}$ of ribavirin was nebulized until dryness and the end of aerosol generation was observed.

Mechanical Ventilation. A passive test lung (QuickLung Jr. Breather, IngMar Medical, Pittsburgh, Pennsylvania) was set with a compliance of $15 \mathrm{~mL} / \mathrm{cm} \mathrm{H}_{2} \mathrm{O}$ and a resistance of $20 \mathrm{~cm} \mathrm{H}_{2} \mathrm{O} / \mathrm{L} / \mathrm{s}$ and connected to a mechanical ventilator (Avea, CareFusion, San Diego, California) that was set to deliver pediatric parameters in the pressure 


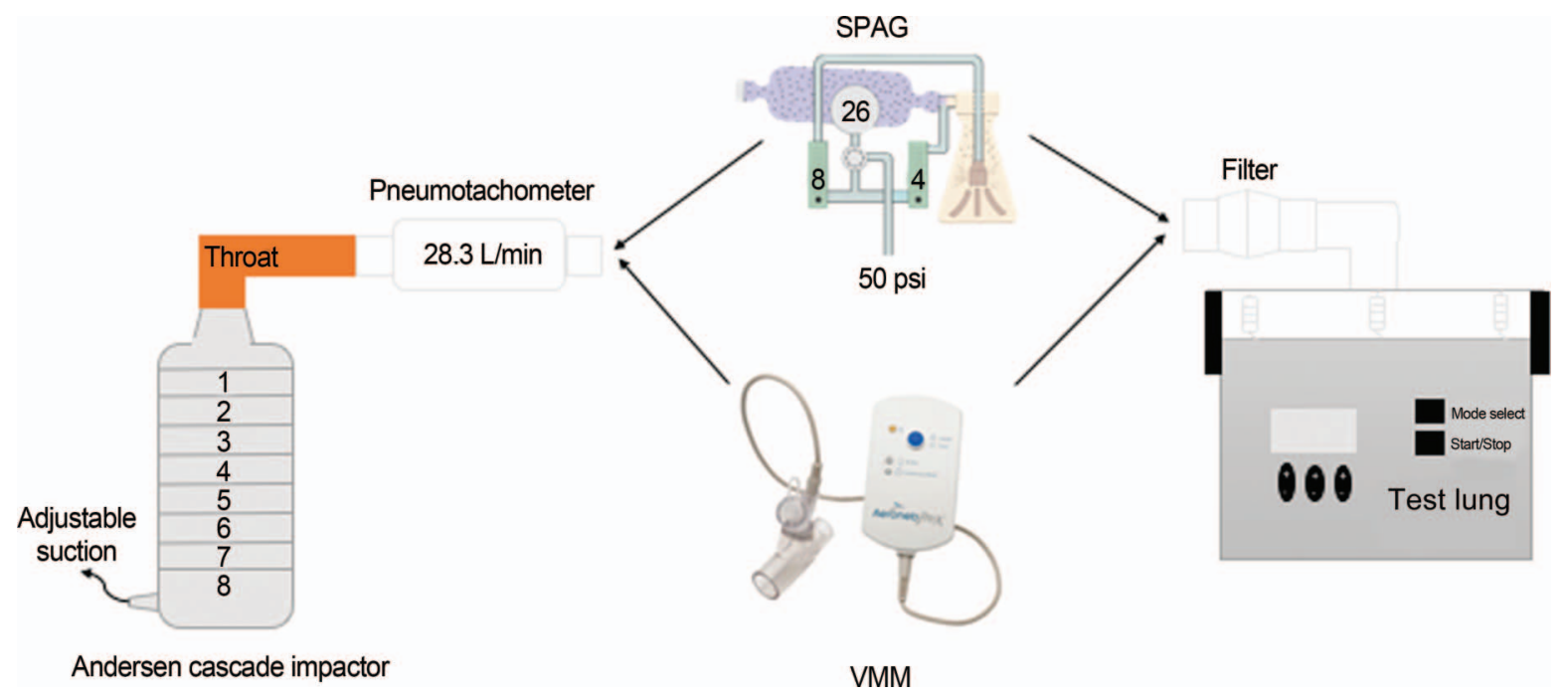

Fig. 1. Experimental setup of particle distribution using the 8-stage Andersen cascade impactor and in vitro module using an absolute filter. The patient simulator was set to passive mode during mechanical ventilation and negative pressure eupnea mode during the spontaneous breathing mode. SPAG = small-particle aerosol generator; VMM = vibrating mesh micropump.

control continuous mandatory ventilation mode, targeting a tidal volume of $200 \mathrm{~mL}$, which required a peak inspiratory pressure of $20 \mathrm{~cm} \mathrm{H}_{2} \mathrm{O}$, PEEP of $5 \mathrm{~cm} \mathrm{H}_{2} \mathrm{O}$, bias flow of $2 \mathrm{~L} / \mathrm{min}$, breathing frequency of 20 breaths/min, and inspiratory-expiratory ratio of 1:3. A heated pass-over wick humidifier (Teleflex, Morrisville, North Carolina) with heated wire circuit set to $37^{\circ} \mathrm{C}$ was set up according to clinical practice. The ventilator circuit (15-mm inner diameter, $3 \mathrm{~m}$ in length) was attached to a $5.0-\mathrm{mm}$ inner diameter endotracheal tube with an absolute filter attached to the distal end of the endotracheal tube and before the passive lung model.

The small-particle aerosol generator-2 nebulizer was set up according to the manufacturer's recommendations for mechanical ventilation, which only uses nebulizer flow (no drying gas applied) with a manufacturerprovided T-piece, pressure-relief valve, and one-way valve placed on the dry side of the humidifier. The small-particle aerosol generator-2 regulator pressure was set to 26 psi with the nebulizer flow set to $8 \mathrm{~L} / \mathrm{min}$. The small-particle aerosol generator-2 was run for 3 sampling periods of $5 \mathrm{~min}$.

The vibrating mesh micropump was positioned with an adult T-piece supplied by the manufacturer placed at the inlet of the humidifier (identical placement of the smallparticle aerosol generator-2). One $\mathrm{mL}$ of formulation was placed in the nebulizer reservoir, and the nebulizer was operated to completion of aerosol generation for 3 sampling periods of approximately $2 \mathrm{~min}$. After each dose, the filter was removed and eluted with $10 \mathrm{~mL}$ of normal saline for 2 min with moderate agitation. Samples were collected and stored for assay.

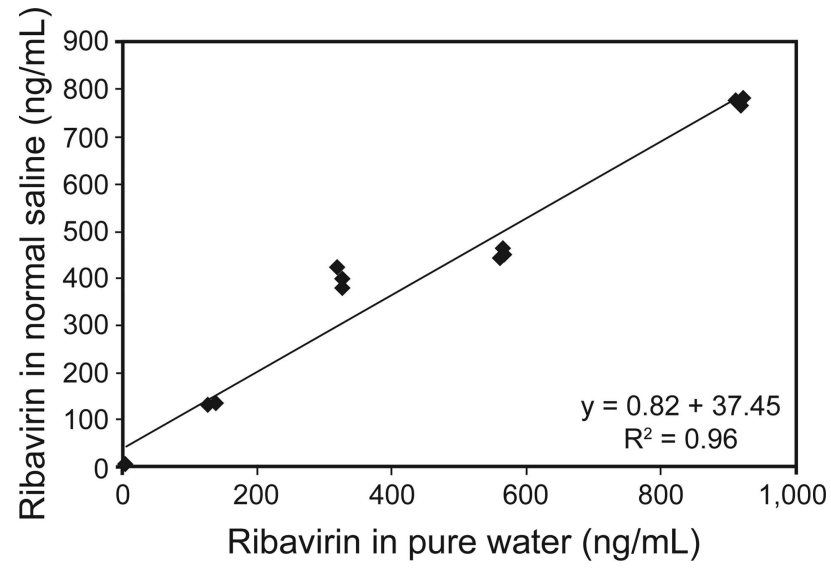

Fig. 2. Correlations of normal saline and pure water demonstrating stability.

\section{Analysis and Data Collection}

The samples were aggressively rinsed from the throat, plate, or filter with sterile $0.9 \%$ saline. Ten milliliters were used for the throat and filters, and $5 \mathrm{~mL}$ were used for each plate. Samples were eluted from the residual fluid and were stored at $-80^{\circ} \mathrm{C}$ for batch assaying after the analytical method was fully developed and validated. Pure standards of ribavirin and bupivacaine, the latter being the internal standard, were purchased from Sigma-Aldrich (St. Louis, Missouri) and used to prepare calibrators in a concentration range of $10-1,000 \mu \mathrm{g} / \mathrm{mL}$. Calibration curves were freshly prepared for each assay batch, which included quality controls and unknowns. From each original sample, $1 \mu \mathrm{L}$ was drawn and diluted 1:1,000 with pure water. The higher concentrations encountered above the upper limits of quantification were further diluted up to $1: 100$ 


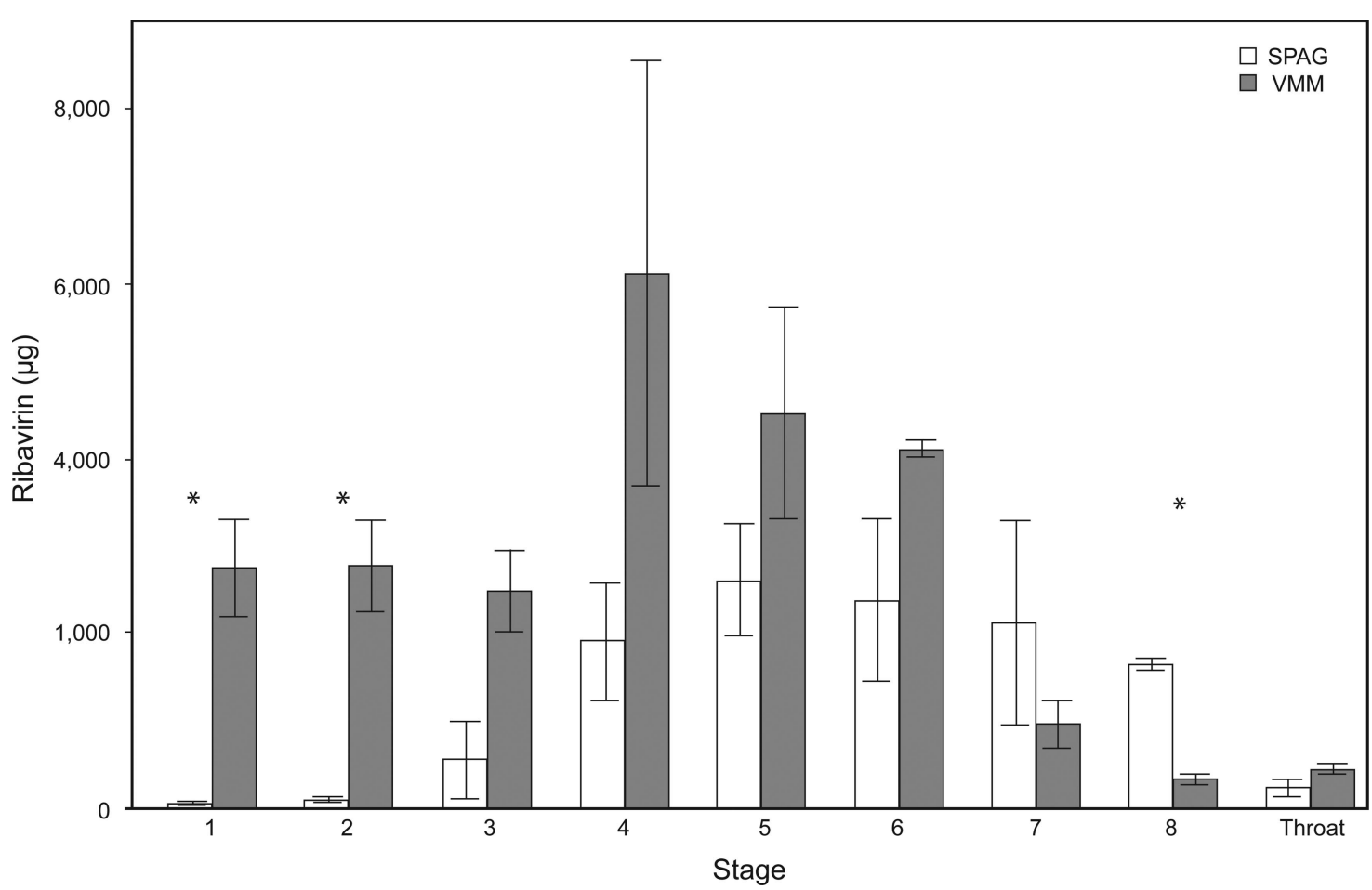

Fig. 3. Particle distribution by size from the small-particle aerosol generator (SPAG) and vibrating mesh micropump (VMM) over 32 -min sampling periods. Table 1 provides additional details for further delineation according to particle size. ${ }^{*} P<.05$.

and reassayed to match the optimal analytical range. The whole method was developed and validated with pure aqueous and normal saline drug solutions.

Samples were processed for the assay of ribavirin by high-performance liquid chromatography/tandem mass spectrometry in an Agilent 1200 and QQQ6410 system. A Phenomenex Security Guard analytical guard column was used together with an Agilent Eclipse XDB-C18 $4.6 \times$ $150 \mathrm{~mm}(5 \mu \mathrm{m})$ analytical column, both at a constant temperature of $38^{\circ} \mathrm{C}$. The mobile phase ran isocratically at a flow of $1.0 \mathrm{~mL} / \mathrm{min}$ and consisted of methanol and aqueous formic acid $(0.1 \%), 50: 50(\mathrm{v} / \mathrm{v})$. The autosampler was kept at a constant $4{ }^{\circ} \mathrm{C}$ temperature, and the injection volume was $5 \mathrm{uL}$.

Detection was carried out with an electrospray ionization, in positive ion mode and with multiple-reaction monitoring. The nebulizer pressure was set at $45 \mathrm{psi}$, the positive capillary was set at $4 \mathrm{kV}$, the gas temperature was set at $300^{\circ} \mathrm{C}$, and the gas flow was set at $11 \mathrm{~L} / \mathrm{min}$. For the acquisition, the ribavirin precursor ion 245.1 was used with product ions 96.0 and 113.0 at a fragmentor voltage of $70 \mathrm{~V}$ and collision energies of 21 and 41 , respectively. For the internal standard, the precursor ion 289.2 was used with product ions 140.1 and 112.1 at a fragmentor voltage of $108 \mathrm{~V}$ and collision energies of 15 and 31, respectively. The cell accelerator voltage was kept at $4 \mathrm{kV}$ throughout.

To assert the equivalency of the ribavirin concentrations between pure water and normal saline, in the range from
Table 1. Drug Mass to the Throat and Andersen Cascade Impactor Stages

\begin{tabular}{lcccrc}
\hline \hline Stage & $\begin{array}{c}\text { Size, } \\
\mu \mathrm{m}\end{array}$ & $\begin{array}{c}\text { Mean Mass With } \\
\text { Vibrating Mesh } \\
\text { Micropump, } \\
\mu \mathrm{g} / \mathrm{mL}\end{array}$ & $\begin{array}{c}\text { Mean Mass } \\
\text { With Small- } \\
\text { Particle Aerosol } \\
\text { Generator, } \mu \mathrm{g} / \mathrm{mL}\end{array}$ & $\begin{array}{c}\text { SE, } \\
\mu \mathrm{g} / \mathrm{mL}\end{array}$ & $P$ \\
\hline Throat & $>9$ & 452.5 & 240.9 & 79.0 & .12 \\
1 & 9 & $2,754.3$ & 69.6 & 530.2 & .041 \\
2 & 5.8 & $2,778.2$ & 104.7 & 508.2 & .034 \\
3 & 4.7 & $2,485.3$ & 561.0 & 901.5 & .16 \\
4 & 3.3 & $6,121.9$ & $1,910.4$ & $1,752.5$ & .14 \\
5 & 2.1 & $4,525.4$ & $2,612.4$ & $1,565.2$ & .35 \\
6 & 1.1 & $4,120.3$ & $2,380.1$ & $1,013.1$ & .23 \\
7 & 0.7 & 958.3 & $2,124.4$ & $1,272.6$ & .46 \\
8 & 0.4 & 336.6 & $1,652.3$ & 122.5 & .009 \\
\hline
\end{tabular}

10 to $1,000 \mu \mathrm{g} / \mathrm{mL}$, both sets of calibrators were run in parallel and later compared against each other. Figure 1 shows a typical ribavirin chromatogram output.

\section{Statistical Data}

A paired $t$ test was used for MMAD, particle size distribution, and cumulative drug delivery calculations between devices. A 2-sample $t$ test and bivariate fit and variance analysis were performed on the drug stability samples, assuming unequal variances. $P$ values of $<.05$ were considered significant. All data presented are means 


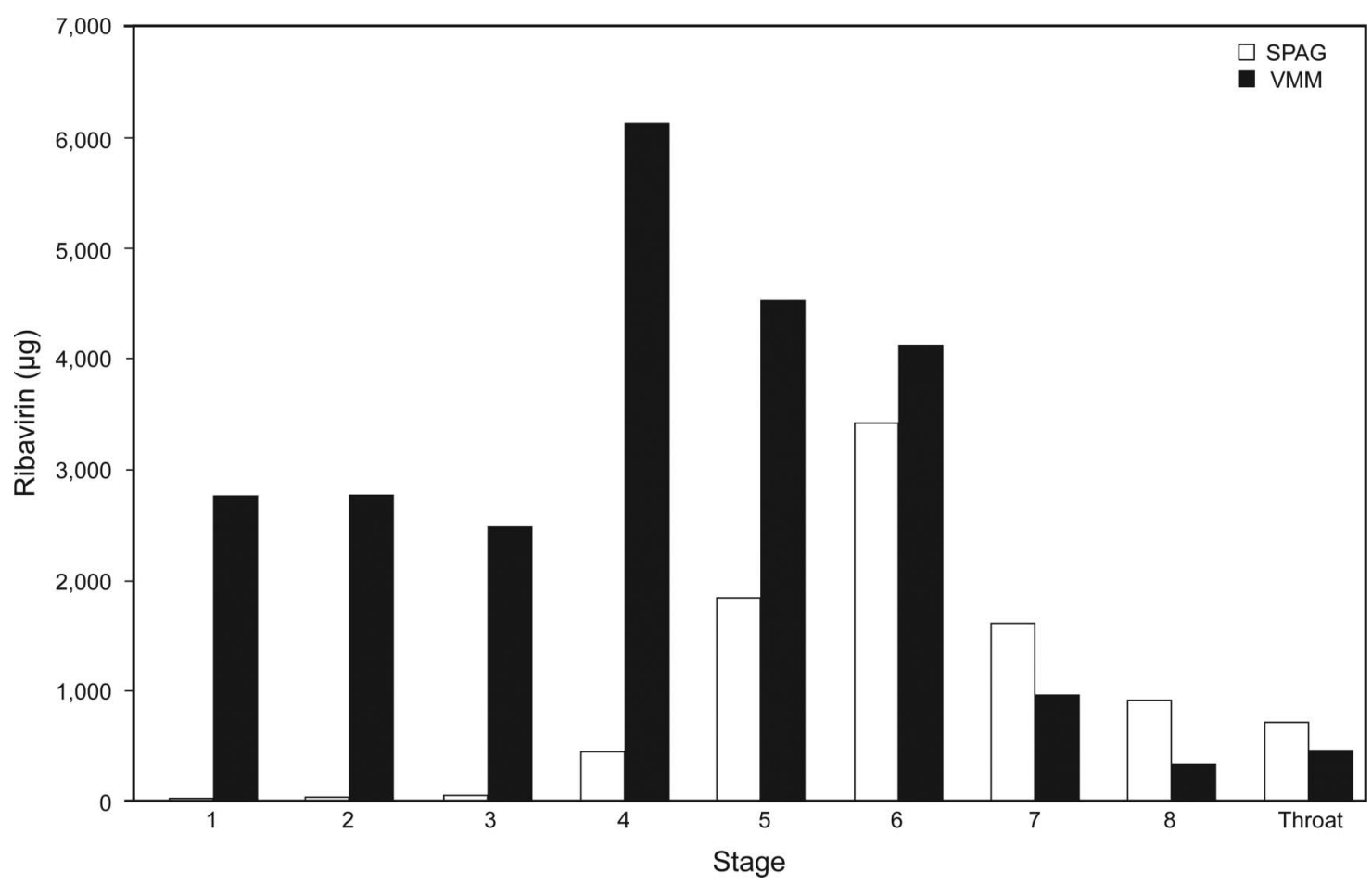

Fig. 4. Particle distribution of vibrating mesh micropump (VMM) under normal operating conditions and small particle aerosol generator (SPAG) with drying gas turned off during a 2-min sampling period. Drying gas is not utilized during mechanical ventilation.

unless otherwise specified. Statistical analyses were conducted using JMP 11 Pro (SAS Institute, Cary, North Carolina).

\section{Results}

\section{Drug Stability}

Ribavirin was found to have similar characteristics when formulated in both $0.9 \%$ aqueous $\mathrm{NaCl}$ and sterile water. Standards prepared in both solvents at concentrations up to $1,000 \mu \mathrm{g} / \mathrm{mL}$ were strongly correlated with an $r^{2}$ of 0.96 , with both formulations having identical coefficients of variation across the concentration range (ie, 2.48 and $2.50 \%$, respectively). When compared using a 2-sample $t$ test assuming unequal variances, $P$ values of .38 and .76 were obtained for the one-sided and 2-sided tests, respectively. Figure 2 demonstrates the normal saline versus water concentration correlation.

\section{Aerosol Generation of Ribavirin by the Vibrating Mesh Micropump}

Concentrations of ribavirin were similar before vibrating mesh micropump $(58,432.9 \pm 25,530.2 \mu \mathrm{g} / \mathrm{mL})$ and after vibrating mesh micropump $(67,817.2 \pm 7,992.8$ $\mu \mathrm{g} / \mathrm{mL})$ nebulization $(P=.37)$. Comparison of chromatographs demonstrated no substantial difference.

\section{Particle Size Distribution}

Condition: Vibrating Mesh Micropump and SmallParticle Aerosol Generator-2 Normal Operation. Drug mass to the throat and Andersen cascade impactor stages are presented in Figure 3 and Table 1. Statistical analyses were performed on all particle ranges (stages) and presented in Table 1 . Stages 1,2 and 8 were statistically significant, with the vibrating mesh micropump delivering more drug than the small-particle aerosol generator- 2 in stages 1 and 2 (larger particles) and the small-particle aerosol generator delivering more drug in stage 8 (smallest particle range). The calculated mean MMAD \pm geometric SD of combined runs during normal operation was significantly different, with the vibrating mesh micropump emitting a $3.63 \pm 1.89-\mu \mathrm{m}$ and the small-particle aerosol generator-2 emitting a smaller $1.84 \pm 1.95-\mu$ m mean particle size $(P=.02, \mathrm{SE}=0.27)$.

Condition: Vibrating Mesh Micropump Normal Operation and Small-Particle Aerosol Generator-2 With Drying Gas Off. The small-particle aerosol generator-2 emitted a statistically lower drug concentration $(1,007.42$ $\mu \mathrm{g} / \mathrm{mL}$ ) throughout all stages when compared with the 
vibrating mesh micropump, which emitted a mean drug concentration of $2,725.89 \mu \mathrm{g} / \mathrm{mL}(\mathrm{SE}=696.89, P=.04)$. See Figure 4.

\section{Drug Delivery}

Condition: Spontaneous Breathing. The small-particle aerosol generator-2 delivered a greater inhaled dose $(20,196.4 \pm 9,093.9 \mu \mathrm{g} / \mathrm{mL})$ than the vibrating mesh micropump $(16,859.3 \pm 8,874.5 \mu \mathrm{g} / \mathrm{mL})$; however, the difference did not reach statistical significance $(P=.77)$.

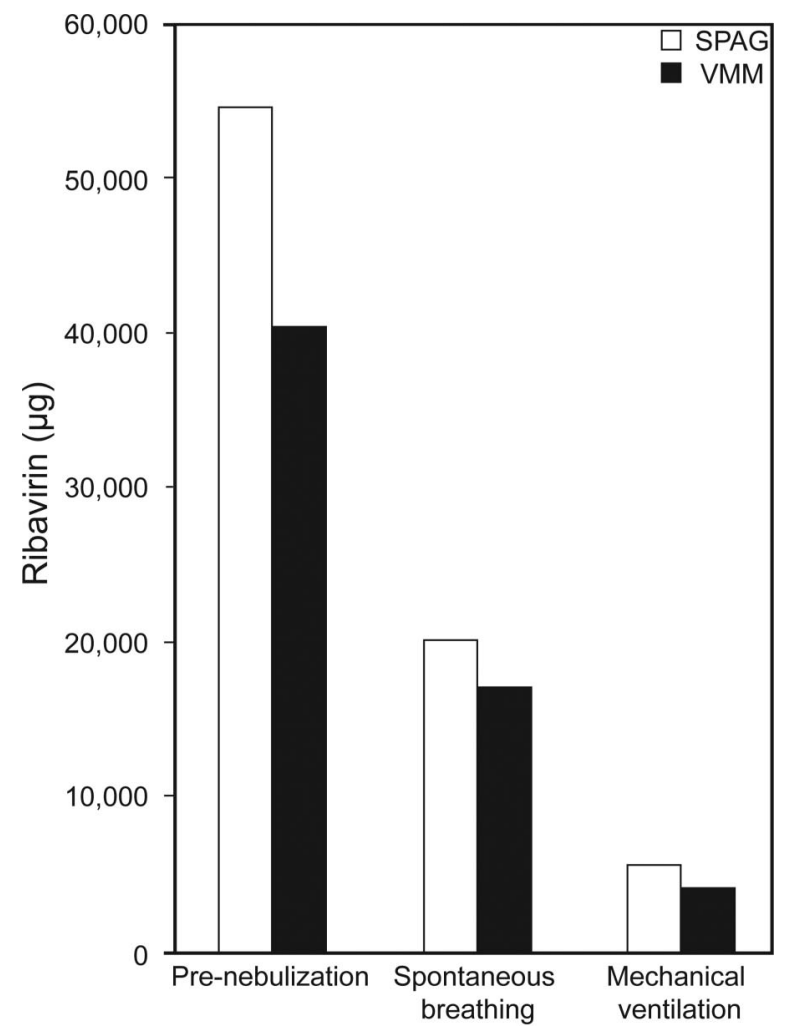

Fig. 5. Total drug dose by device and condition while delivering 1 $\mathrm{mL}$ of ribavirin ( $5 \mathrm{~min}$ for the small-particle aerosol generator [SPAG] or 2 min for the vibrating mesh micropump [VMM]). Shown are the inhaled dose during spontaneous breathing and inhaled dose during mechanical ventilation. Table 2 provides additional details and percentage of drug delivery. Results before nebulization were used to calculate the percentage of inhaled dose.
When calculating the percentage of total drug delivered (pre- vs post-nebulizer) the vibrating mesh micropump delivered more drug (41.8\% vs $36.9 \%)$. See Figure 5 and Table 2 for details.

Condition: Mechanical Ventilation. Drug delivered distal to the endotracheal tube was similar with the smallparticle aerosol generator-2 $(5,669.9 \pm 1,011.2 \mu \mathrm{g} / \mathrm{mL})$ and the vibrating mesh micropump $(3,816.2 \pm 2,745.5$ $\mu \mathrm{g} / \mathrm{mL}, P=.48)$. When calculating the percentage of total drug delivered, the small-particle aerosol generator delivered slightly more drug (10.4\% vs $9.5 \%)$ but was not considered significant. See Figure 5 for details.

\section{Discussion}

This is the first paper comparing administration of inhaled ribavirin with the small-particle aerosol generator-2 and any potential alternate aerosol generator. We found that the integrity of the drug was not altered when reconstituted with $0.9 \% \mathrm{NaCl}$ compared with sterile water. Anecdotal reports have associated with an increase in use of inhaled bronchodilators for children receiving ribavirin mixed in sterile water. This is despite that fact that smaller particles would contain less of the sterile water due to evaporation. However, with the larger particles generated by the vibrating mesh micropump, we would anticipate that the use of sterile water would be problematic for patients over extended administration. This is of practical importance because inhalation of sterile water has been associated with irritation of the airways, as evidenced by cough and bronchospasm. Although the use of normal saline is typically better tolerated when inhaled as aerosol, it does represent a variation from the manufacturer's label for drug preparation and would be considered off-label administration.

We observed no change in the chromatograph between pre- and post-nebulization with the vibrating mesh micropump. This testing was limited to the vibrating mesh micropump, which adds no gas to the aerosol, allowing the collection of emitted aerosol in a tube, where particles rain out and are readily available for testing. Unfortunately, the high gas flow from the small-particle aerosol generator-2 made similar sampling impossible, and we were concerned

Table 2. Drug Delivery by Vibrating Mesh Micropump and Small-Particle Aerosol Generator

\begin{tabular}{|c|c|c|c|c|c|c|}
\hline Condition & $\begin{array}{l}\text { Mean Mass Before } \\
\text { Small-Particle } \\
\text { Aerosol Generator, } \mu \mathrm{g} / \mathrm{mL}\end{array}$ & $\begin{array}{l}\text { Mean Mass Before } \\
\text { Vibrating Mesh } \\
\text { Micropump, } \mu \mathrm{g} / \mathrm{mL}\end{array}$ & $\begin{array}{c}\text { Mean Mass of } \\
\text { Delivery by } \\
\text { Small-Particle Aerosol } \\
\text { Generator, } \mu \mathrm{g} / \mathrm{mL}(\%)\end{array}$ & $\begin{array}{l}\text { Mean Mass of } \\
\text { Delivery by } \\
\text { Vibrating Mesh } \\
\text { Micropump, } \\
\mu \mathrm{g} / \mathrm{mL}(\%)\end{array}$ & $\mathrm{SE}, \mu \mathrm{g} / \mathrm{mL}$ & $P$ \\
\hline Spontaneous breathing & $54,632.3$ & $40,380.3$ & 20,196.4 (36.9) & $16,859.3(41.8)$ & $9,802.3$ & .77 \\
\hline Mechanical ventilation & $54,632.3$ & $40,380.3$ & $5,669.9(10.4)$ & $3,816.2(9.5)$ & $2,127.7$ & .48 \\
\hline
\end{tabular}


that collection and eluting drug from a filter might alter the results. However, our primary concern was the impact of the vibrating mesh micropump on the drug substance,

Our findings of particle size characteristics with the small-particle aerosol generator are consistent with those of Newth and Clark, ${ }^{11}$ with their reported MMAD of $1.2 \mu \mathrm{m}$ versus our finding of $1.8 \mu \mathrm{m}$. Differences may be attributed to the different types of impactors used (liquid impinger vs Anderson cascade impactor). The larger MMAD generated by the vibrating mesh micropump was consistent with data provided by the manufacturer. We found no other reports of small-particle aerosol generator-2 performance since 1988.

\section{Large Versus Small Volume Nebulizers}

Due to the smaller reservoir volume of the vibrating mesh micropump, the use of continuous feed (as supplied by the manufacturer) would be required for extended administration times. This could be as simple as setting the syringe pump to $12 \mathrm{~mL} / \mathrm{h}$ to match the output for the small-particle aerosol generator- 2 described on the product label. Evaluation of use of the continuous feed set with the vibrating mesh micropump or possible changes in the concentration of drug within large volume nebulizers over time was beyond the scope of the study and should be rigorously undertaken in the future.

\section{Limitations}

Since this paper has suggested that the vibrating mesh nebulizer may effectively provide inhaled doses comparable with those with the small-particle aerosol generator-2 during spontaneous breathing and mechanical ventilation, an issue remains as to how this relates to clinical use and potential regulatory approval as a new method of delivery. This process would probably require some level of clinical trials to gain regulatory approval (a process that would require multiple years and millions of dollars). Our findings suggest that clinical evaluation of the small-particle aerosol generator and vibrating mesh micropump may be warranted in the future.

Due to the expense of the drug, we were not able to test aerosol output across the entire recommended treatment period of $2 \mathrm{~h}$ under each condition. Similarly, we only tested on a set of representative ventilatory parameters for both spontaneous and mechanical ventilation. Future studies should compare the consistency of aerosol characteristics across recommended treatment times with a broader range of infant, pediatric, and adult parameters.

\section{Clinical Impact}

The use of the vibrating mesh micropump as an alternative and potentially simpler mechanism for the admin- istration of aerosolized ribavirin is intriguing. This is the first study to quantify both particle size distribution and emitted dose of ribavirin with the small-particle aerosol generator-2 and compare these with the newer vibrating mesh micropump technology. At present, ribavirin is primarily used to treat immunocompromised patients who develop respiratory syncytial virus and has been shown to be effective at halting the progression of infection from the upper to the lower respiratory tract and at reducing the associated morbidity and mortality. ${ }^{4}$ Aerosol delivery has been minimized when possible due to the cumbersomeness of the small-particle aerosol generator- 2 system and the need to use containment canopies or controlled air handling to protect caregivers from potential exposure. ${ }^{19}$ Although oral and intravenous preparations have been effective, they do not act directly on the respiratory mucosa and are associated with adverse effects, such as neutropenia. ${ }^{20} \mathrm{~A}$ number of centers have been administering inhaled ribavirin to transplant patients, requiring prolonged delivery by mask or mouthpiece. This study establishes important groundwork for the administration of aerosolized ribavirin with an alternate aerosol delivery system, and although caregiver exposure remains a concern, the efficiency of the vibrating mesh micropump may permit shorter treatment durations.

\section{Conclusions}

Ribavirin is stable in $0.9 \%$ aqueous $\mathrm{NaCl}$, which makes it suitable for administration by the vibrating mesh micropump nebulizer. The small-particle aerosol generator produces a smaller MMAD than the vibrating mesh micropump; however, the drug mass in the respirable range was similar. The vibrating mesh micropump nebulizer is an effective alternative to the small-particle aerosol generator in administration of ribavirin both on and off the ventilator. Further studies are needed to compare efficiency of the vibrating mesh micropump to deliver a prescribed dose in a shorter time frame.

\section{REFERENCES}

1. Chu HY, Englund JA. Respiratory syncytial virus disease: prevention and treatment. Curr Top Microbiol Immunol 2013;372:235-258.

2. Ventre K, Randolph AG. Ribavirin for respiratory syncytial virus infection of the lower respiratory tract in infants and young children. Cochrane Database Syst Rev 2007;(1):CD000181.

3. Neemann K, Freifeld A. Respiratory syncytial virus in hematopoietic stem cell transplantation and solid-organ transplantation. Curr Infect Dis Rep 2015;17(7):490.

4. Shah DP, Ghantoji SS, Shah JN, El Taoum KK, Jiang Y, Popat U, et al. Impact of aerosolized ribavirin on mortality in 280 allogeneic haematopoietic stem cell transplant recipients with respiratory syncytial virus infections. J Antimicrob Chemother 2013;68(8):18721880 . 


\section{Characterization of Ribavirin Aerosol With 2 Aerosol Technologies}

5. Fätkenheuer G, Gillor D, Platten M, Kochanek M, Salzberger B. Aerosolized ribavirin for patients with cancer and respiratory syncytial virus infection. J Infect Dis 2013;207(10):1621.

6. Seo S, Campbell AP, Xie H, Chien JW, Leisenring WM, Englund JA, Boeckh M. Outcome of respiratory syncytial virus lower respiratory tract disease in hematopoietic cell transplant recipients receiving aerosolized ribavirin: significance of stem cell source and oxygen requirement. Biol Blood Marrow Transplant 2013;19(4):589596.

7. Chemaly RF, Torres HA, Munsell MF, Shah DP, Rathod DB, Bodey GP, et al. An adaptive randomized trial of an intermittent dosing schedule of aerosolized ribavirin in patients with cancer and respiratory syncytial virus infection. J Infect Dis 2012;206(9):1367-1371.

8. Gilbert BE, Knight V. Biochemistry and clinical applications of ribavirin: antimicrobial agents and chemotherapy 1986;30(2):201205.

9. Englund JA, Piedra PA, Jefferson LS, Wilson SZ, Taber LH, Gilbert BE. High-dose, short-duration ribavirin aerosol therapy in children with suspected respiratory syncytial virus infection. J Pediatr 1990; 117(2 Pt 1):313-320.

10. Smith DW, Frankel LR, Mathers LH, Tang AT, Ariagno RL, Prober CG. A controlled trial of aerosolized ribavirin in infants receiving mechanical ventilation for severe respiratory syncytial virus infection. N Engl J Med 1991;325(1):24-29.

11. Newth CJ, Clark AR. In vitro performance of the small particle aerosol generator (SPAG-2). Pediatr Pulmonol 1989;7(3):183-188.

12. Waldrep JC, Dhand R. Advanced nebulizer designs employing vibrating mesh/aperture plate technologies for aerosol generation. Curr Drug Deliv 2008;5(2):114-119.
13. Zhang G, David A, Wiedmann TS. Performance of the vibrating membrane aerosol generation device: Aeroneb Micropump Nebulizer. J Aerosol Med 2007;20(4):408-416.

14. Golshahi L, Longest PW, Azimi M, Syed A, Hindle M. Intermittent aerosol delivery to the lungs during high-flow nasal cannula therapy. Respir Care 2014;59(10):1476-1486.

15. Perry SA, Kesser KC, Geller DE, Selhorst DM, Rendle JK, Hertzog $\mathrm{JH}$. Influences of cannula size and flow rate on aerosol drug delivery through the Vapotherm humidified high-flow nasal cannula system. Pediatr Crit Care Med 2013;14(5):e250-e256.

16. Ari A, Harwood R, Sheard M, Dailey P, Fink JB. In vitro comparison of heliox and oxygen in aerosol delivery using pediatric high flow nasal cannula. Pediatr Pulmonol 2011;46(8):795-801.

17. Sidler-Moix AL, Di Paolo ER, Dolci U, Berger-Gryllaki M, Cotting J, Pannatier A. Physicochemical aspects and efficiency of albuterol nebulization: comparison of three aerosol types in an in vitro pediatric model. Respir Care 2015;60(1):38-46.

18. Standardization IOf. Anaesthetic and respiratory equipment: nebulizing systems and components

19. Molinos-Quintana A, Pérez-de Soto C, Gómez-Rosa M, Pérez-Simon JA, Pérez-Hurtado JM. Intravenous ribavirin for respiratory syncytial viral infections in pediatric hematopoietic SCT recipients. Bone Marrow Transplant 2013;48(2):265-268.

20. Gueller S, Duenzinger U, Wolf T, Ajib S, Mousset S, Berger A, et al. Successful systemic high-dose ribavirin treatment of respiratory syncytial virus-induced infections occurring pre-engraftment in allogeneic hematopoietic stem cell transplant recipients. Transpl Infect Dis 2013;15(4):435-440.

This article is approved for Continuing Respiratory Care Education credit. For information and to obtain your CRCE

(free to AARC members) visit

www.rcjournal.com

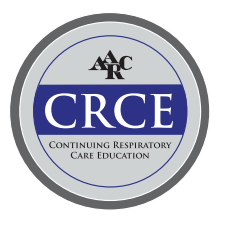

